\title{
Synthesis and anticancer evaluation of some novel pyrimido[5,4-e][1,2,4]triazines and pyrazolo[3,4- $d$ ]pyrimidine using DMF-DMA as methylating and cyclizing agent
}

Samar A. El-Kalyoubi ${ }^{1,2^{*}}$

\begin{abstract}
Background: Described a series of main target compounds pyrimido[5,4-e][1,2,4]triazines is obtained via condensation of 6-hydrazinyluracil with different aromatic aldehydes to give the hydrazones followed by nitrosation with $\mathrm{HNO}_{2}$ then intramolecular cyclization. On the other hand, pyrazolopyrimidines can be obtained by the reaction of hydrazones with dimethylformamide-dimethylacetal (DMF-DMA), DMF-DMA in the presence of DMF or by refluxing the hydrazinyluracil with DMF-DMA in the presence of DMF directly. The newly synthesized compounds are evaluated in vitro for their anticancer activity against human lung carcinoma (A549).

Results: A newly substituted compounds of benzaldehyde-pyrimidin-4-yl)hydrazones (5a-f), pyrimido[5,4-e][1,2,4]triazines $\mathbf{6 a}-\mathbf{e}$, arylethylidenehydrazinylpyrimidine $\mathbf{7 a}, \mathbf{b}$ and pyrazolopyrimidines $\mathbf{9 , 1 1}$ are screened for cytotoxic activity against human lung carcinoma (A549) cell line. They exhibited a good yield. Compound $\mathbf{6 b}$ shows the highest effect with $\mathrm{I}_{50}$ value $3.6 \mu \mathrm{M}$, followed by compounds $\mathbf{9}, \mathbf{5 a}, \mathbf{8}, \mathbf{5 e}, \mathbf{6 e}, \mathbf{5 b}, \mathbf{5 f}, \mathbf{7 a}, \mathbf{5 c}, \mathbf{6 c}, \mathbf{7 b}, \mathbf{6 a}, \mathbf{1 1}, \mathbf{5 d}$ and $\mathbf{6 d}$.

Conclusion: A simple and efficient route is used for the synthesis of pyrimido[5,4-e][1,2,4]triazines and pyrazolopyrimidines. The synthesized compounds are screened for antitumor activity.

Keywords: 6-Hydrazinyluracil, Pyrimidotriazine, Pyrazolopyrimidine, Dimethylformamide-dimethylacetal, Anticancer activities
\end{abstract}

\section{Background}

Triazine is analogues of six membered benzene ring via replacing the three carbon atoms with nitrogens. 1,2,4-triazine and their fused ring structures with one or more heterocycles represent an important class of nitrogen heterocycles compounds. It possess the motif part of naturally and synthetic pharmaceutical products
[1-9]. They exhibit a broad spectrum biological effects [10] with antibacterial [11, 12], antitumor [13, 14], anticonvulsant [15], anti-inflammatory [16], and antiviral properties [17]. 6-Azacytosine and 6-azauracil are used as effective antiviral and antitumor activities [18-21]. The tirapazamine (TPZ) is efficacious in the treatment of different human cancer cells via inducing DNA damage in poorly oxygenated tumor cells [22].

\footnotetext{
*Correspondence: s.elkalyoubi@hotmail.com

1 Department of Pharmaceutical Organic Chemistry, Faculty of Pharmacy

(Girls), Al-Azhar University, Nasr City, Cairo 11651, Egypt

Full list of author information is available at the end of the article
} 
<smiles>Nc1cn[nH]c(=O)n1</smiles>

\section{6-Azacytosine}

The pyrimidotriazine antibiotics represent a wide spectrum of both antimicrobial and antitumor activities [23]. Pyrimido[5,4-e][1,2,4] triazine constitutes the essential active ingredient of the antibiotics like fervenulin (which is formed from actinomyces), xanthothricin, and reumycin [2, 3]. Reumycin [24] is isolated from actinomyces rectus bruneus and used as an antitumor antibiotic for treating brain tumors. Other hetero annelated 1,2,4-triazines have clinical antiviral effect against influenza A and B viruses [4], anti-HIV and anticancer activity [5, 6]. They also show antimicrobial, antifungal effects and cytotoxicity to MCF-7 cells [7, 8]. Fervenulin (planomycin), and its tautomeric isomer toxoflavin (panthothricin) \{1.6-dimethylpyrimido[5,4-e][1,2,4] triazine-5,7 $(1 \mathrm{H}, 6 \mathrm{H})$ dione\} reveal a wide spectrum antibacterial, antifungal, herbicidal and anticancer activities [25-27].<smiles>Cn1c(=O)c2ncnnc2n(C)c1=O</smiles>

Fervenulin<smiles></smiles>

Toxoflavin<smiles>Nc1n[n+]([O-])c2ccccc2[n+]1[O-]</smiles>

Tirapazamine

\section{Result and discussion Chemistry}

In continuation to our research, the importance of fervenulin and its diverse pharmacological activity on the medical field, especially as antitumors, we became interested in the prospect of developing our strategies to synthesize new fervenulin analogues of pyrimidotriazine and pyrazolopyrimidine derivatives using 6-hydrazinyl-1-propyluracil (4) as a core for construction. This substrate is prepared via simple hydrolysis of 2,4,6-trichloropyrimidine [37] followed by N-1 selective alkylation using propyl iodide in DMSO in the presence of potassium carbonate as a basic medium [38] then hydrazinolysis of 6-chloro-1-propyluracil (3) with hydrazine hydrate [38-40]. Condensation of substrate 4 with

\section{Rheumycin}

Pyrazolopyrimidines constitute the core of many drugs with wide variety of applications in the field of medicine. They are bioactive isomeric purine analogues and have a significant activity as antimetabolites in purine biochemical reactions [28-31]. They have diverse pharmacological effect as tuberculostatic [32], antimicrobial activities [33], neuroleptic [34], CNS depressant [32], antihypertensive [35] and antileishmanial [36].

In this regard, our strategy is directed towards the synthesis of new pyrimido[5,4-e][1,2,4]triazine and pyrazolopyrimidine compounds because they have found wide applications in pharmaceutical fields. The structure of newly synthesized pyrimidotriazines and pyrazolopyrimidines are proven on the basis of their ${ }^{1} \mathrm{H}-\mathrm{NMR}$, mass spectral data, IR and elemental analysis. different aromatic aldehydes in ethanol at room temperature for $1 \mathrm{~h}$ leads to the formation of hydrazones $\mathbf{5 a}-\mathbf{f}$ in a good yield (Scheme 1).

The IR spectra of hydrazones displayed the $\mathrm{N}-\mathrm{H}$ stretching bands at $3271-3122 \mathrm{~cm}^{-1}$. The stretching band of the two $\mathrm{C}=\mathrm{O}$ groups (Amide $\mathrm{I}$ ) is displayed within the range 1740-1625 $\mathrm{cm}^{-1}$. Compound 5d showed $\mathrm{O}-\mathrm{H}$ stretching bands at $3560 \mathrm{~cm}^{-1}$ while the nitro group in compound 5e shows strong asymmetric and symmetric $\mathrm{NO}_{2}$ stretching bands at 1514 and $1337 \mathrm{~cm}^{-1}$, respectively. The ${ }^{1} \mathrm{H}$-NMR spectra supported the previous observation from the IR spectra, where $\mathrm{N} 3-\mathrm{H}$ and C6- $\mathrm{NH}$ is highly deshielded. They appeared around $\delta$ 10.75-10.05 ppm, while the $\alpha-\mathrm{CH}$ of hydrazone appeared at the range $\delta 8.48-8.24 \mathrm{ppm}$. The $\mathrm{C} 5-\mathrm{H}$ was the most 
<smiles>Clc1cc(Cl)nc(Cl)n1</smiles>

1<smiles>CC(C)C</smiles>

2<smiles>CCCn1c(Cl)cc(=O)[nH]c1=O</smiles>

3<smiles>CCCn1c(NN)cc(=O)[nH]c1=O</smiles>

4

$\mathrm{R}=\mathrm{H}, 4-\mathrm{Cl}, 4-\mathrm{Br}, 4-\mathrm{OH}, 4-\mathrm{NO}_{2}, 4-\mathrm{N}\left(\mathrm{CH}_{3}\right)_{2}$<smiles>[R]c1cccc(-c2nnc3c(n2)c(=O)[nH]c(=O)n3CCC)c1</smiles>

$\mathrm{R}=\mathrm{H}, 4-\mathrm{Cl}, 4-\mathrm{Br}, 4-\mathrm{OH}, 4-\mathrm{NO}_{2}$

Scheme 1 Reaction of 6-hydrazinyluracil with different aromatic aldehydes and formation of pyrimidotriazines. $a=\mathrm{NaOH} / \mathrm{H}_{2} \mathrm{O} / \mathrm{Reflux} ; \mathrm{b}=\mathrm{Prl} /$ $\mathrm{K}_{2} \mathrm{CO}_{3} / \mathrm{DMSO} ; \mathrm{C}=\mathrm{NH}_{2} \mathrm{NH}_{2} \cdot \mathrm{H}_{2} \mathrm{O} / \mathrm{rt} ; \mathrm{d}=\mathrm{ArCHO} / \mathrm{EtOH} / \mathrm{rt} ; \mathrm{e}=\mathrm{NaNO}_{2} / \mathrm{AcOH} /$ Reflux

shielded as expected around $\delta 5.46-5.30 \mathrm{ppm}$. The downfield shift of the $\alpha$-carbon of hydrazone appeared around $\delta 145 \mathrm{ppm}$ in the ${ }^{13} \mathrm{C}$-NMR spectra.

Pyrimidotriazines $\mathbf{6 a}-\mathbf{e}$ is isolated by the nitrosation of hydrazone compounds $\mathbf{5 a}-\mathbf{e}$ at $\mathrm{C}-5$ with in situ prepared nitrous acid. The inseparable 5-nitroso-derivatives undergoes cyclization via the nucleophilic attack of the electron rich $\alpha$-carbon of the hydrazones on the nitroso group to form hydroxylamine intermediates, which are converted into the target pyrimidotriazines $\mathbf{6 a}-\mathbf{e}$ by protonation of the $N$-hydroxyl group followed by the elimination of $\mathrm{H}_{3} \mathrm{O}^{+}$(Scheme 2). The IR spectra of $\mathbf{6 a}-\mathbf{e}$ displayed broad absorption bands of $\mathrm{NH}$ stretching in the region of $3180-3135 \mathrm{~cm}^{-1}$. The two bands of $\mathrm{C}=\mathrm{O}$ groups gave rise in the region of $1725-1670 \mathrm{~cm}^{-1}$.

Moreover, the cyclization of the hydrazone series are confirmed in ${ }^{1} \mathrm{H}$-NMR spectra through the disappearance of both the $\alpha-\mathrm{CH}$ hydrazone at $\delta 8.48-8.24 \mathrm{ppm}$ and the $\mathrm{C} 5-\mathrm{H}$ of uracil at $\delta 5.46-5.30 \mathrm{ppm}$. 


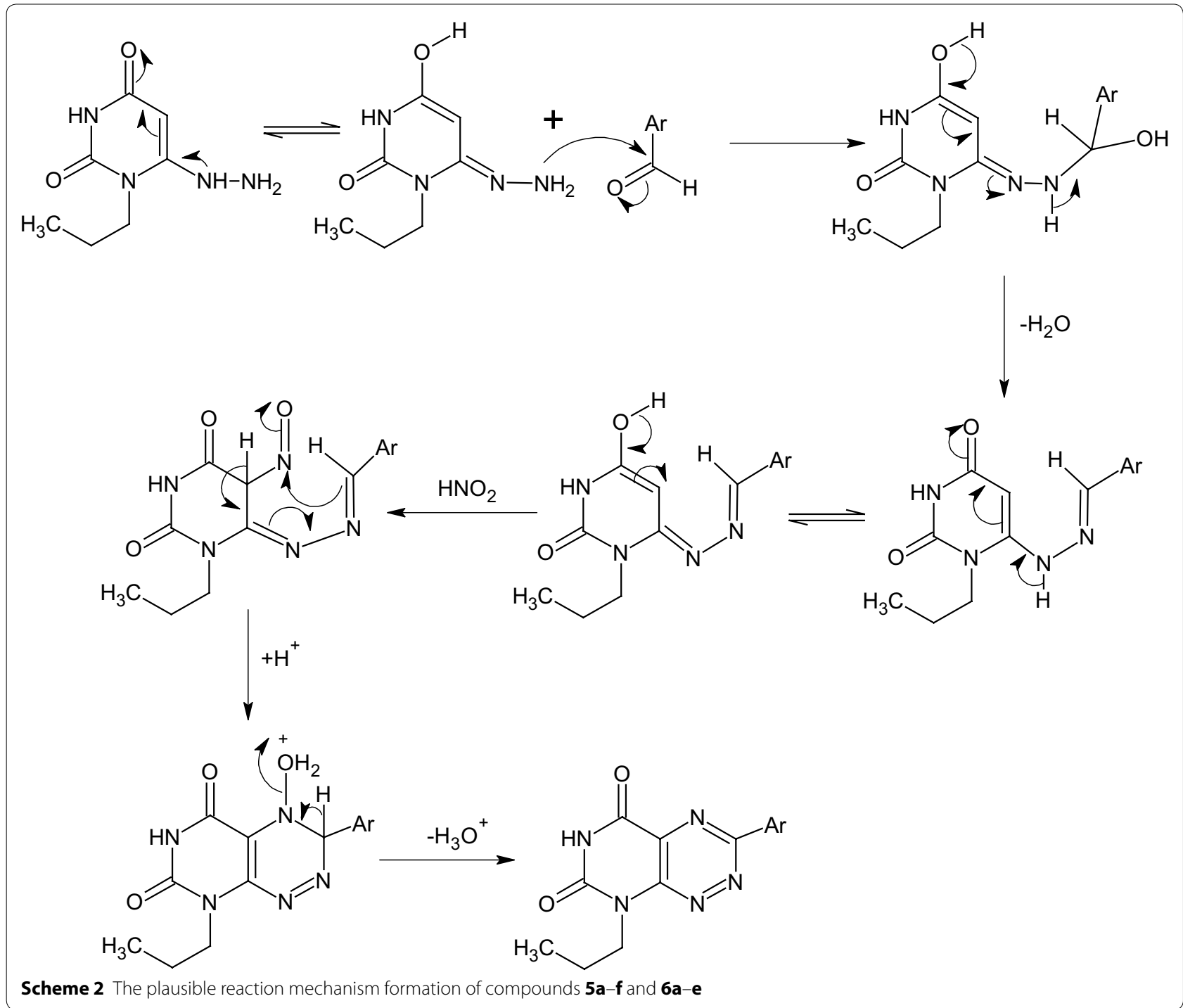

Another condensation reaction is obtained via condensation of $\mathbf{4}$ with different acetophenones by stirring at room temperature for 3-4 h (Scheme 3). The IR spectra of $7 \mathbf{a}, \mathbf{b}$ displayed stretching bands at the range of $3188-3154 \mathrm{~cm}^{-1}$ due to $\mathrm{N}-\mathrm{H}$ absorption and characteristic bands at the range $1715-1691 \mathrm{~cm}^{-1}$ due to absorption of $\mathrm{C}=\mathrm{O}$ groups. The mass spectra of these compounds show the expected molecular ions, whereas their ${ }^{1} \mathrm{H}-\mathrm{NMR}$ spectra exhibited two signals at $\delta 11.11-$ $11.06 \mathrm{ppm}$ and at $\delta 9.13-8.96 \mathrm{ppm}$ ascribed for $\mathrm{N} 3-\mathrm{H}$ and $\mathrm{C} 6-\mathrm{NH}$ protons respectively. The singlet signals of the methyl group protons at the $\alpha$-carbon appeared at $\delta$ 2.42-2.37 ppm while for the $\mathrm{CH}-5$ position appeared at $\delta 5.48-5.39 \mathrm{ppm} .{ }^{13} \mathrm{C}$-NMR confirmed the structure of $7 \mathbf{a}, \mathbf{b}$ where the key signals at $\delta 78.8-79.8 \mathrm{ppm}$ and $\delta$ 14.3-14.2 ppm are assigned to $s p^{2}$ carbon at position 5 and $s p^{3}$ carbon attached to the $\alpha$-carbon respectively.
The target compound 9 is prepared by refluxing of $7 \mathbf{a}$ with DMF-DMA for $12 \mathrm{~h}$ or DMF-DMA in presence of DMF as a solvent for $1 \mathrm{~h}$ (Scheme 3). DMF-DMA is a convenient electrophile to introduce one-carbon units. The reaction proceeds via nucleophilic attack of C-5 to electrophilic carbon center of acetal in DMF-DMA followed by intramolecular cyclization and elimination of dimethylamine. A subsequent methylation of NH-5 is observed which arises from $\mathrm{O}-\mathrm{CH}_{3}$ group of the acetal not $\mathrm{N}-\mathrm{CH}_{3}$ as illustrated in Scheme 4. The plausible mechanism is proved by isolation of the intermediate $\mathbf{8}$. This intermediate is easily identified in IR, Mass, ${ }^{1} \mathrm{H}-\mathrm{NMR}$ and ${ }^{13} \mathrm{C}$ NMR spectra. A broad stretching absorption band of $\mathrm{NH}$ appears at the region of $3136 \mathrm{~cm}^{-1}$ of the intermediate 8 in IR spectra and disappears in the target compound 9. Furthermore, ${ }^{1} \mathrm{H}$-NMR showed the disappearance of $\mathrm{CH}-5$ proton at $\delta 5.48-5.39 \mathrm{ppm}$ and the appearance of a 


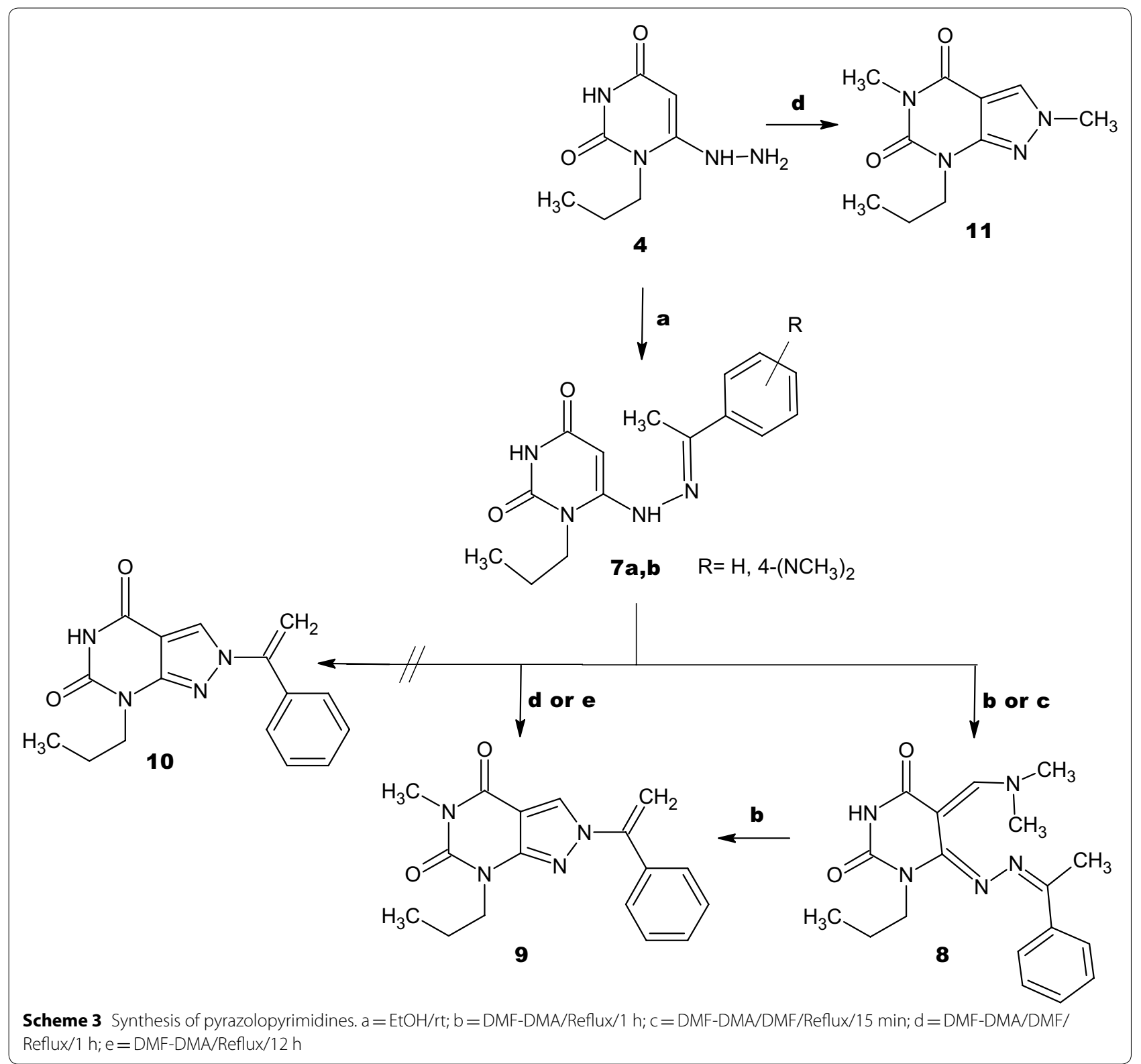

singlet signal at $\delta 8.08$ ppm characteristic for $\mathrm{CH}-\mathrm{N}$ proton, a singlet signal of $\alpha-\mathrm{C}-\mathrm{CH}_{3}$ at $\delta 2.39 \mathrm{ppm}$ and two characteristic $\mathrm{N}-\mathrm{CH}_{3}$ group at $\delta 3.19,3.05 \mathrm{ppm}$ of compound 8 and disappears in compound 9 due to the elimination of dimethylamine (Scheme 4).

Whereas, the alkylation on N-5 in compound 9 is proven without doubt by the disappearance of a singlet signal of NH-5 proton at $\delta 10.13 \mathrm{ppm}$ and the appearance of the $s p^{3}$ singlet signal at $\delta 3.23 \mathrm{ppm}$ characteristic of $\mathrm{CH}_{3}$ appears in ${ }^{1} \mathrm{H}-\mathrm{NMR}$ and a signal at $\delta 27.6 \mathrm{ppm}$ in ${ }^{13} \mathrm{C}$-NMR. In addition, the ${ }^{1} \mathrm{H}$-NMR shows a singlet signal of $\mathrm{CH}-3$ at $\delta 8.60 \mathrm{ppm}$ and two doublet signals at $\delta 5.71-5.61 \mathrm{ppm}$ corresponding to the two protons of methylene group which indicates that they are not magnetically equivalent. ${ }^{13} \mathrm{C}$-NMR shows the appearance of signals at $\delta 134.2$ and $101.7 \mathrm{ppm}$ characteristic for C-3 and methylene carbon atom respectively.

Treatment of 4 with DMF-DMA in the presence of DMF by refluxing for $1 \mathrm{~h}$ yielded compound $\mathbf{1 1}$ (Scheme 3). IR spectra shows characteristic absorption band at $1751,1698 \mathrm{~cm}^{-1}$ for $\mathrm{C}=\mathrm{O}$ groups. ${ }^{1} \mathrm{H}-\mathrm{NMR}$ spectrum displays three singlet signals at $\delta 8.41,3.88$ and $3.19 \mathrm{ppm}$ for $\mathrm{CH}-3, \mathrm{~N}(2)-\mathrm{CH}_{3}$ and $\mathrm{N}(5)-\mathrm{CH}_{3}$ respectively. On the other hand, ${ }^{13} \mathrm{C}$-NMR showed $\mathrm{C}-\mathrm{N}(2)$ at $\delta$ $40.4 \mathrm{ppm}$ and $\mathrm{C}-\mathrm{N}(5)$ at $\delta 27.5 \mathrm{ppm}$ which confirms the alkylation of N(5) with DMF-DMA. The plausible mechanism for this reaction is shown in (Scheme 5). 


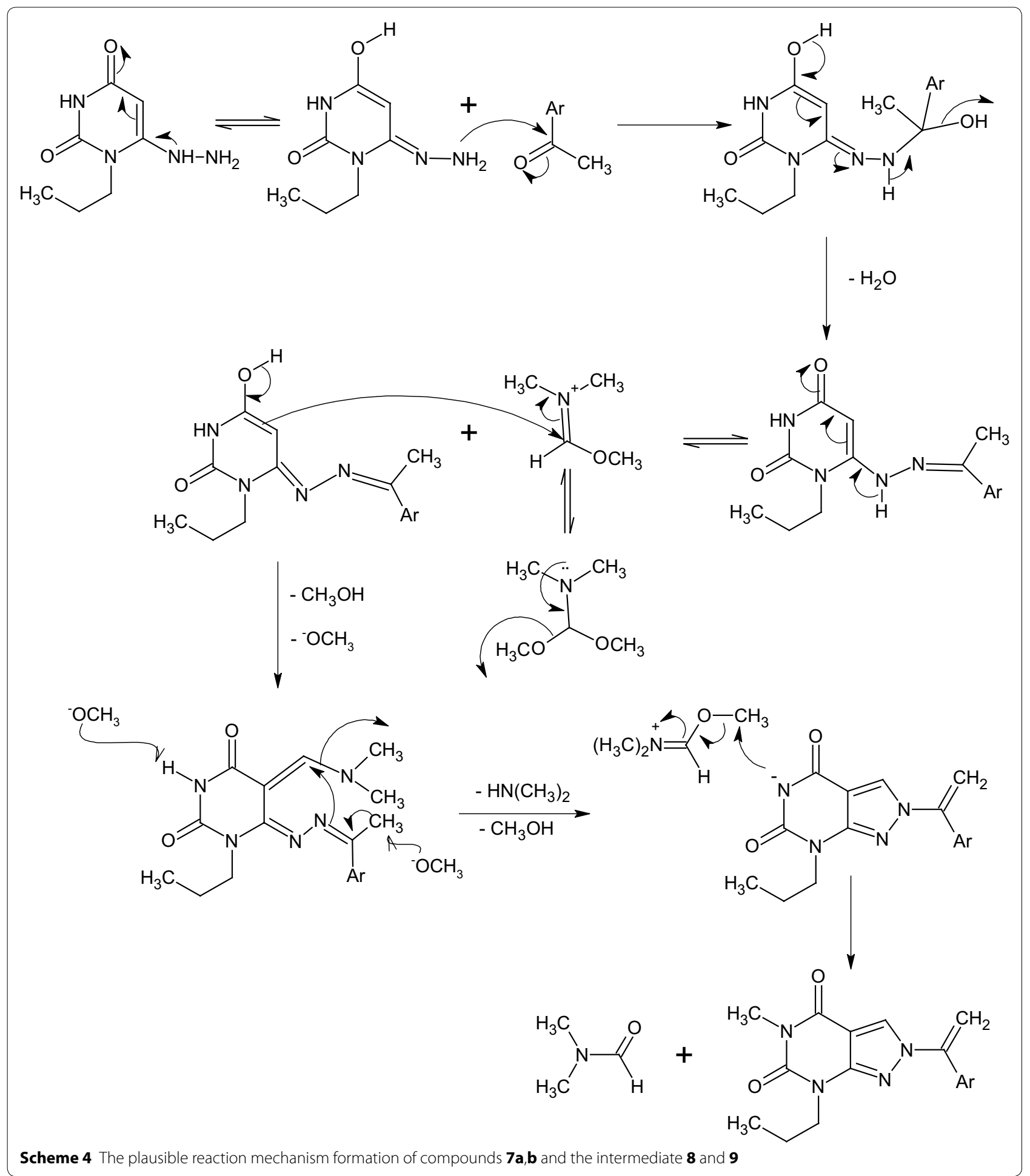

\section{Biological investigation}

\section{Cytotoxic activity}

The in vitro growth inhibitory rates against human lung carcinoma (A549) cell line and effective antitumor doses (as measured by $\mathrm{IC}_{50}$ ) of the synthesized compounds are investigated in comparison with the well-known anticancer standard drugs toxoflavin and 5-fluorouracil, using crystal violet colorimetric viability assay. Data generated 


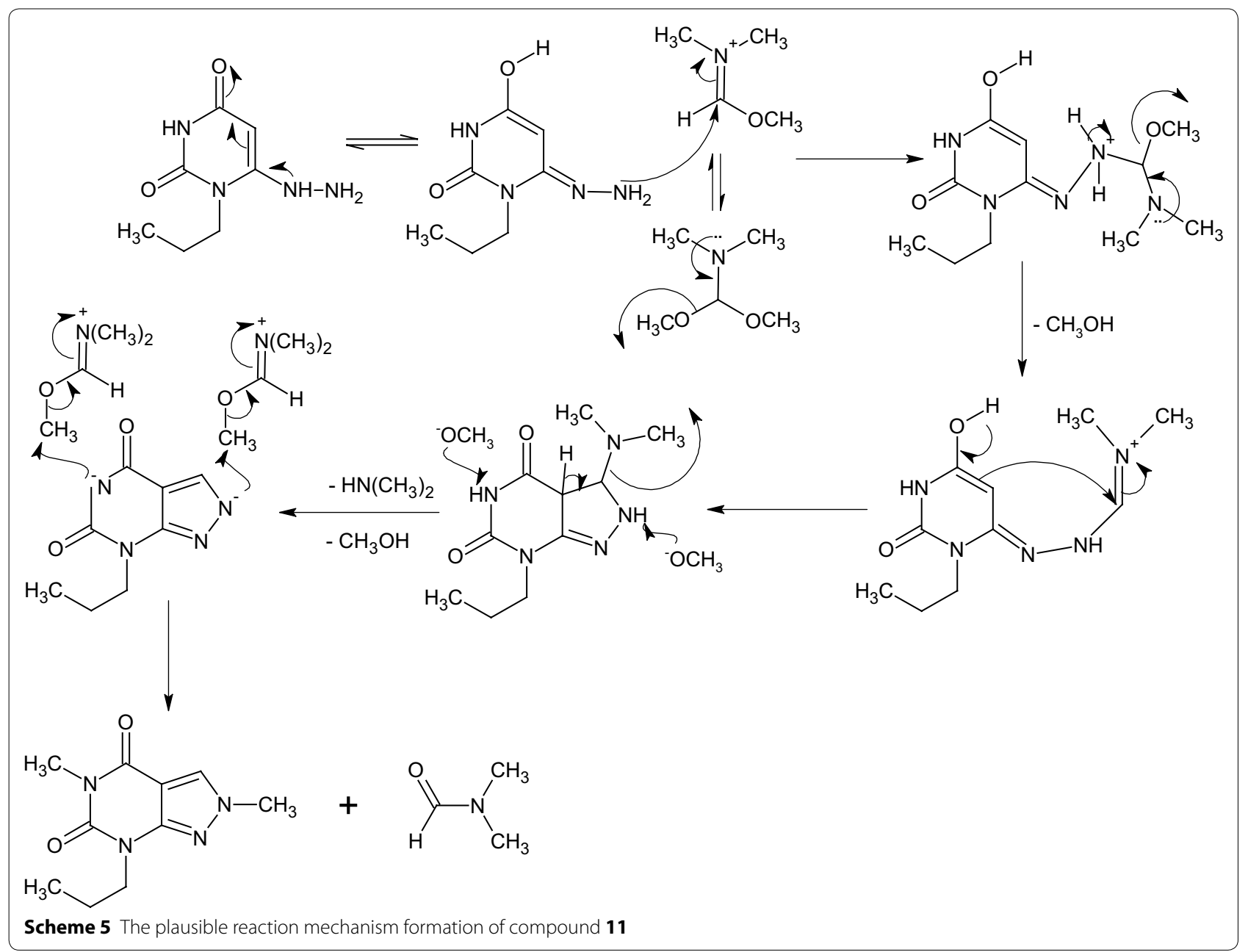

are used to plot dose response curves and presented in Table 1 and Fig. 1 . The results reveal that all the tested compounds show high variation in the inhibitory growth rates and activities to the tumor cell line in a concentration dependent manner as shown in (Table 1).

Table 1 The $I C_{50}$ values represent the compound concentration $(\mu \mathrm{M})$ required to inhibit A549 tumor cell proliferation by $\mathbf{5 0 \%}$

\begin{tabular}{lclc}
\hline Compounds & $\mathbf{I C}_{\mathbf{5 0}}(\boldsymbol{\mu M})$ & Compounds & $\mathbf{I C}_{\mathbf{5 0}}(\boldsymbol{\mu M})$ \\
\hline $\mathbf{5 a}$ & $26.8 \pm 1.3$ & $\mathbf{6 c}$ & $81.5 \pm 4.3$ \\
$\mathbf{5 b}$ & $54.7 \pm 2.1$ & $\mathbf{6 d}$ & $379.4 \pm 24.8$ \\
$\mathbf{5 c}$ & $74.3 \pm 5.1$ & $\mathbf{6 e}$ & $53.8 \pm 3.5$ \\
$\mathbf{5 d}$ & $238.7 \pm 12.5$ & $\mathbf{7 a}$ & $60.5 \pm 2.6$ \\
$\mathbf{5 e}$ & $49.3 \pm 4.1$ & $\mathbf{7 b}$ & $104.6 \pm 4.8$ \\
$\mathbf{5 f}$ & $60.2 \pm 3.2$ & $\mathbf{8}$ & $28.4 \pm 1.6$ \\
$\mathbf{6 a}$ & $107.1 \pm 6.2$ & $\mathbf{9}$ & $26.3 \pm 0.9$ \\
$\mathbf{6 b}$ & $3.6 \pm 0.2$ & $\mathbf{1 1}$ & $123 \pm 6.1$ \\
Toxoflavin $^{\mathrm{a}}$ & $0.7 \pm 0.1$ & a5-FU & $10.5 \pm 0.1$ \\
\hline
\end{tabular}

a Reference drugs; 5-FU (5-fluorouracil)
From the results in Fig. 1, it is clear that all the tested compounds are found to be very active at $500 \mu \mathrm{M}$ against human lung carcinoma (A549) cell line after treatment for $72 \mathrm{~h}$ with inhibition ratio values between 60 and $97 \%$. The difference between inhibitory activities of all compounds with different concentrations is statistically significant $(\mathrm{p}<0.001)$.

The highest activity against human lung carcinoma (A549) cell line is measured for compound $\mathbf{6 b}$ with $\mathrm{IC}_{50}$ value $3.6 \mu \mathrm{M}$, followed by compounds $\mathbf{9}, \mathbf{5 a}, \mathbf{8}, \mathbf{5 e}, \mathbf{6 e}$, $\mathbf{5 b}, \mathbf{5 f}, \mathbf{7 a}, \mathbf{5 c}, \mathbf{6 c}, \mathbf{7 b}, \mathbf{6 a}, \mathbf{1 1}, \mathbf{5 d}$ and $\mathbf{6 d}$ with $\mathrm{IC}_{50}$ values of $26.3,26.8,28.4,49.3,53.8,54.7,60.2,60.5,74.3,81.5$, 104.6, 107.1, 123, 238.7, and 379.4 $\mu \mathrm{M}$, compared with reference drugs 5 -fluorouracil $(10.5 \mu \mathrm{M})$ and toxoflavin $(0.7 \mu \mathrm{M})$.

\section{Methods}

Instruments

All melting points were determined with an electrothermal melting-temperature II apparatus and are uncorrected. Element analyses are performed at the regional 

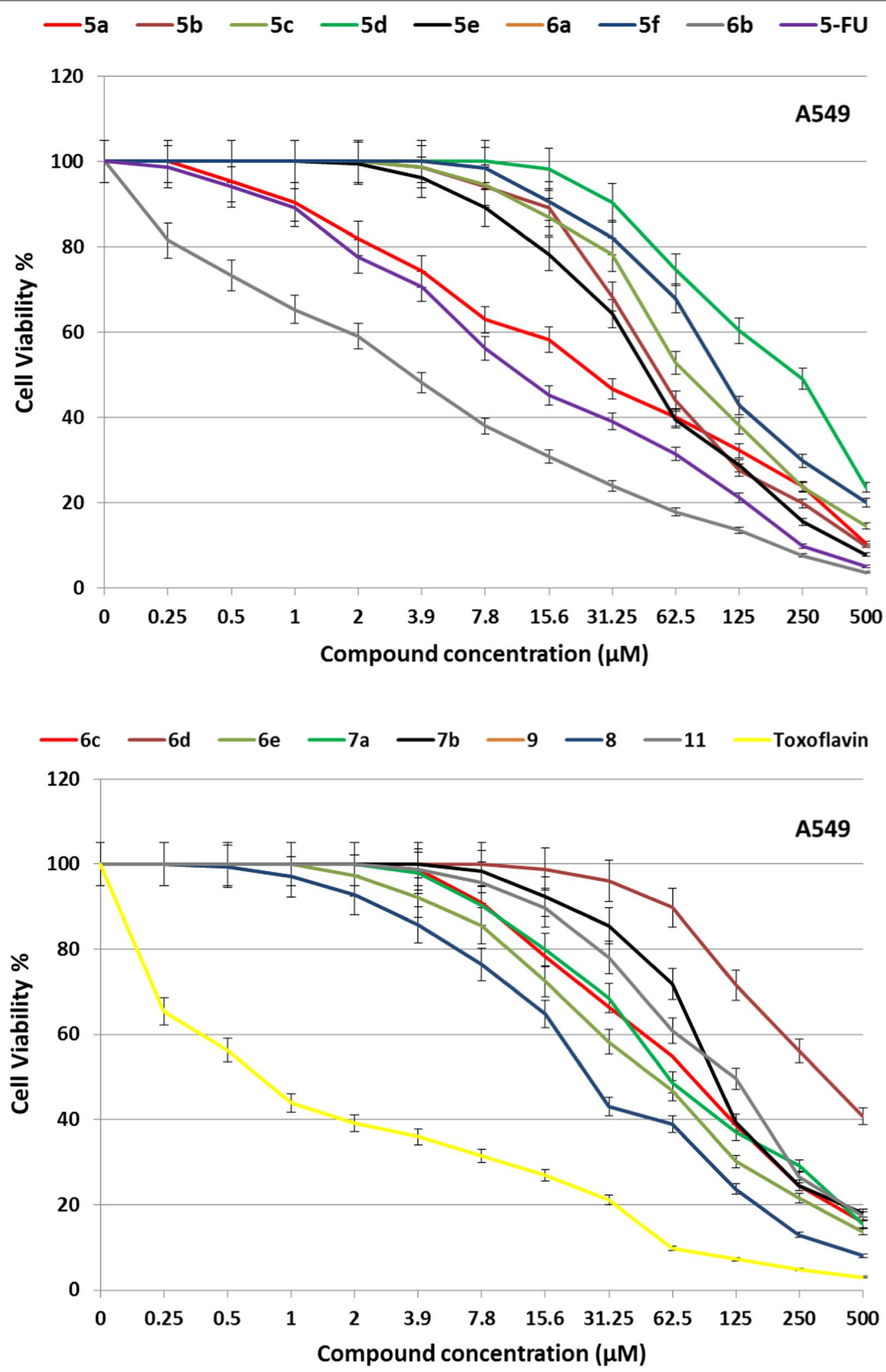

Fig. 1 Growth inhibition curves showing A549 cell line treated with the tested compounds at different concentrations compared with reference drugs 5 -flourouracil and toxoflavin 
center for mycology and biotechnology at Al-Azhar University. The infrared (IR) spectra are recorded using potassium bromide disc technique on Nikolet IR 200 FT IR. Mass spectra are recorded on a DI-50 unit of Shimadzu GC/MS-QP 5050A at the regional center for mycology and biotechnology at Al-Azhar University. ${ }^{1} \mathrm{H}$-NMR and ${ }^{13} \mathrm{C}$-NMR spectra are determined on Bruker $400 \mathrm{MHz}$ spectrometer using DMSO- $\mathrm{d}_{6}$ as a solvent, applied nucleic acid research center, Zagazig University, Egypt. All reactions are monitored by TLC using precoated plastic sheets silica gel (Merck $\left.60 \mathrm{~F}_{254}\right)$. Spots are visualized by irradiation with UV light $(254 \mathrm{~nm})$. The used solvent system is chloroform: methanol (9:1) and ethyl acetate: toluene (1:1).

\section{Synthesis}

6-Chlorouracil (2) was prepared according to the reported method [37].

6-Chloro-1-propyluracil (3) was prepared according to the reported method [38].

6-Hydrazinyl-1-propyluracil (4) [38-40].

\section{4-Substituted benzaldehyde(2,6-dioxo-3-propyl-1,2,3,6-tet- rahydropyrimidin-4-yl)hydrazones (5a-f)}

A mixture of 6-hydrazinyl-1-propyluracil (4) (2.17 mmol) and appropriate benzaldehydes $(2.17 \mathrm{mmol})$ in ethanol $(25 \mathrm{~mL})$ is stirred at room temperature for $1 \mathrm{~h}$. The formed precipitate is collected by filtration, washed with ethanol and crystallized from ethanol.

\section{Benzaldehyde(2,6-dioxo-3-propyl-1,2,3,6-tetrahydropyrimi- din-4-yl)hydrazone (5a)}

Yield: 83\%; m.p. $=218-219{ }^{\circ} \mathrm{C}$; IR $(\mathrm{KBr}) v_{\max }\left(\mathrm{cm}^{-1}\right)$ : $3224(\mathrm{NH}), 3045$ ( $\mathrm{CH}$ arom.), 2969, 2908 (CH aliph.), 1739, $1647(\mathrm{C}=\mathrm{O}), 1550(\mathrm{C}=\mathrm{N}), 1516(\mathrm{C}=\mathrm{C}) ;{ }^{1} \mathrm{H}-\mathrm{NMR}$ $\left(\right.$ DMSO- $\left.d_{6}\right): 10.69(\mathrm{~s}, 1 \mathrm{H}, \mathrm{NH}), 10.38(\mathrm{~s}, 1 \mathrm{H}, \mathrm{NH}), 8.39(\mathrm{~s}$, $1 \mathrm{H}, \mathrm{CH}), 7.73-7.71\left(\mathrm{~d}, 2 \mathrm{H}, J=7.6 \mathrm{~Hz}, \mathrm{H}_{\text {arom }}\right), 7.45-7.42$ (m, 3H, arom.), $5.38(\mathrm{~s}, 1 \mathrm{H}, \mathrm{CH}-5), 3.89-3.85(\mathrm{t}, 2 \mathrm{H}$, $\left.\mathrm{CH}_{2}\right), 1.60-1.55\left(\mathrm{~m}, 2 \mathrm{H}, \mathrm{CH}_{2}\right), 0.91-0.87\left(\mathrm{t}, 3 \mathrm{H}, \mathrm{CH}_{3}\right)$; ${ }^{13} \mathrm{C}$-NMR (DMSO- $d_{6}$ ): $\delta=162.4,152.4,151.0,146.5$, 134.0, 130.0, 128.9, 126.9, 77.2, 42.2, 21.0, 10.7 ppm; MS: $m / z(\%)=\mathrm{M}^{+}, 272$ (83), 243 (61), 216 (36), 153 (36), 145 (31), 144 (25), 110 (27), 106 (58), 104 (100), 103 (22), 90 (38), 89 (33), 77 (52); Anal. calcd. for $\mathrm{C}_{14} \mathrm{H}_{16} \mathrm{~N}_{4} \mathrm{O}_{2}$ (272.30): C, 61.75; H, 5.92; N, 20.58. Found: C, 61.86; H, 5.97; N, 20.73.

\section{4-Chlorobenzaldehyde(2,6-dioxo-3-propyl-1,2,3,6-tetrahy- dropyrimidin-4-yl)hydrazone (5b)}

Yield: 85\%; m.p. $=238-239{ }^{\circ} \mathrm{C}$; IR $(\mathrm{KBr}) v_{\max }\left(\mathrm{cm}^{-1}\right): 3224$ (NH), 3056 (CH arom.), 2936 (CH aliph.), 1700, 1630 $(\mathrm{C}=\mathrm{O}), 1594(\mathrm{C}=\mathrm{N}), 1558(\mathrm{C}=\mathrm{C}), 870$ (p-substituted phenyl); ${ }^{1} \mathrm{H}-\mathrm{NMR}$ (DMSO- $d_{6}$ ): $10.68(\mathrm{~s}, 1 \mathrm{H}, \mathrm{NH}), 10.42$ (s, $1 \mathrm{H}, \mathrm{NH}), 8.37(\mathrm{~s}, 1 \mathrm{H}, \mathrm{CH}), 7.75-7.73(\mathrm{~d}, 2 \mathrm{H}, J=8.4 \mathrm{~Hz}$, $\left.\mathrm{H}_{\text {arom }}\right), 7.51-7.49\left(\mathrm{~d}, 2 \mathrm{H}, J=8.4 \mathrm{~Hz}, \mathrm{H}_{\text {arom }}\right), 5.39(\mathrm{~s}, 1 \mathrm{H}$, CH-5), 3.89-3.85 (t, 2H, CH 0.90-0.87 (t, $\left.3 \mathrm{H}, \mathrm{CH}_{3}\right) ;{ }^{13} \mathrm{C}-\mathrm{NMR}$ (DMSO- $\left.d_{6}\right): \delta=162.4$, 152.4, 151.0, 145.1, 134.4, 133.0, 129.0, 128.5, 77.4, 42.2, 21.0, $10.7 \mathrm{ppm}$; MS: $m / z(\%)=\mathrm{M}+2,308(31), \mathrm{M}^{+}, 306$ (100), 279 (30), 277 (96), 252 (22), 250 (64), 179 (31), 178 (27), 154 (12), 153 (52), 152 (39), 142 (23), 140 (82), 139 (33), 138 (86), 136 (63), 127 (27), 125 (17), 124 (25), 113 (22), 111 (48), 110 (37); Anal. calcd. for $\mathrm{C}_{14} \mathrm{H}_{15} \mathrm{ClN}_{4} \mathrm{O}_{2}$ (306.74): C, 54.82; H, 4.93; N, 18.26. Found: C, 55.04; H, $5.01 ; \mathrm{N}, 18.43$.

4-Bromobenzaldehyde(2,6-dioxo-3-propyl-1,2,3,6-tetrahydropyrimidin-4-yl)hydrazone (5c)

Yield: 84\%; m.p. $=242-243{ }^{\circ} \mathrm{C}$; IR $(\mathrm{KBr}) v_{\max }\left(\mathrm{cm}^{-1}\right): 3122$ (NH), 3028 (CH arom.), 2971 (CH aliph.), 1740, 1647 $(\mathrm{C}=\mathrm{O}), 1548(\mathrm{C}=\mathrm{N}), 1515(\mathrm{C}=\mathrm{C}), 869$ (p-substituted phenyl); ${ }^{1} \mathrm{H}-\mathrm{NMR}$ (DMSO- $\left.d_{6}\right): 10.68(\mathrm{~s}, 1 \mathrm{H}, \mathrm{NH}), 10.43$ (s, 1H, NH), 8.36 (s, 1H, CH), 7.70-7.63 (m, 4H, arom.), 5.39 (s,1H, CH-5), 3.89-3.85 (t, 2H, $\left.\mathrm{CH}_{2}\right), 1.60-1.54(\mathrm{~m}$, $2 \mathrm{H}, \mathrm{CH}_{2}$ ), 0.90-0.84 (t, 3H, $\mathrm{CH}_{3}$ ); ${ }^{13} \mathrm{C}-\mathrm{NMR}$ (DMSO$\left.d_{6}\right): \delta=162.5,152.4,151.0,145.2,133.3,131.9,128.7$, 123.2, 77.4, 42.2, 21.0, 10.7 ppm; MS: $m / z(\%)=M+2$, 353 (6), M+ 351 (12), 350 (77), 323 (23), 321 (68), 296 (61), 294 (100), 186 (50), 183 (48), 182 (47), 181 (44), 168 (30), 157 (36), 154 (20), 253 (27), 152 (56), 144 (41), 140 (33), 110 (31), 102 (23), 89 (47), 76 (41); Anal. calcd. for $\mathrm{C}_{14} \mathrm{H}_{15} \mathrm{BrN}_{4} \mathrm{O}_{2}$ (351.20): C, 47.88; H, 4.3; N, 15.95. Found: C, 48.02; H, 4.28; N, 16.02 .

4-Hydroxybenzaldehyde(2,6-dioxo-3-propyl-1,2,3,6-tetrahydropyrimidin-4-yl)hydrazone (5d)

Yield: 78\%; m.p. $=213-214{ }^{\circ} \mathrm{C}$; IR $(\mathrm{KBr}) v_{\max }\left(\mathrm{cm}^{-1}\right): 3560$ $(\mathrm{OH}), 3271(\mathrm{NH}), 3020$ ( $\mathrm{CH}$ arom.), 2968 ( $\mathrm{CH}$ aliph.), 1705, $1625(\mathrm{C}=\mathrm{O}), 1581(\mathrm{C}=\mathrm{N}), 1512(\mathrm{C}=\mathrm{C}), 834$ (p-substituted phenyl); ${ }^{1} \mathrm{H}-\mathrm{NMR}$ (DMSO- $\left.d_{6}\right): 10.58(\mathrm{~s}, 1 \mathrm{H}, \mathrm{NH})$, 10.15 (s, 1H, NH), 9.90 (s, 1H, OH), $8.28(\mathrm{~s}, 1 \mathrm{H}, \mathrm{CH})$, 7.56-7.53 (d, 2H, J=8.4 Hz, $\left.\mathrm{H}_{\text {arom }}\right), 6.84-6.82(\mathrm{~d}, 2 \mathrm{H}$, $\left.J=8.4 \mathrm{~Hz}, \mathrm{H}_{\text {arom }}\right), 5.32(\mathrm{~s}, 1 \mathrm{H}, \mathrm{CH}-5), 3.87-3.85(\mathrm{t}, 2 \mathrm{H}$, $\left.\mathrm{CH}_{2}\right), 1.59-1.57\left(\mathrm{~m}, 2 \mathrm{H}, \mathrm{CH}_{2}\right), 0.90-0.87\left(\mathrm{t}, 3 \mathrm{H}, \mathrm{CH}_{3}\right) ;{ }^{13} \mathrm{C}-$ NMR (DMSO- $\left.d_{6}\right): \delta=162.5,159.4,152.5,151.1,147.0$, 128.7, 125.1, 115.8, 76.6, 42.1, 21.0, $10.7 \mathrm{ppm}$; MS: $\mathrm{m} / z$ $(\%)=\mathrm{M}^{+}, 288$ (40), 259 (21), 232 (31), 161 (72), 160 (48), 146 (24), 122 (61), 121 (26), 120 (88), 119 (100), 106 (30), 1105 (20); Anal. calcd. for $\mathrm{C}_{14} \mathrm{H}_{16} \mathrm{~N}_{4} \mathrm{O}_{3}$ (288.30): C, 58.32; H, 5.59; N, 19.43. Found: C, 58.50; H, 5.67; N, 19.61 .

4-Nitrobenzaldehyde(2,6-dioxo-3-propyl-1,2,3,6-tetrahydropyrimidin-4-yl)hydrazone (5e)

Yield: 91\%; m.p. $=228-230{ }^{\circ} \mathrm{C}$; IR $(\mathrm{KBr}) v_{\max }\left(\mathrm{cm}^{-1}\right): 3150$ (NH), 3022 (CH arom.), 2968 (CH aliph.), 1740, 1692 $(\mathrm{C}=\mathrm{O}), 1593(\mathrm{C}=\mathrm{N}), 1561(\mathrm{C}=\mathrm{C}), 1514 \quad\left(\mathrm{NO}_{\text {2asymstr }}\right)$, 
$1337\left(\mathrm{NO}_{2 \text { symstr }}\right), 843$ (p-substituted phenyl); ${ }^{1} \mathrm{H}-\mathrm{NMR}$ (DMSO- $\left.d_{6}\right): 10.75(\mathrm{~s}, 1 \mathrm{H}, \mathrm{NH}), 10.68(\mathrm{~s}, 1 \mathrm{H}, \mathrm{NH}), 8.48$ (s, $1 \mathrm{H}, \mathrm{CH}), 8.28-8.26\left(\mathrm{~d}, 2 \mathrm{H}, J=7.2 \mathrm{~Hz}, \mathrm{H}_{\text {arom }}\right), 7.99-$ 7.97 (d, $2 \mathrm{H}, J=7.2 \mathrm{~Hz}, \mathrm{H}_{\text {arom }}$ ), 5.46 (s, $\left.1 \mathrm{H}, \mathrm{CH}-5\right), 3.90-$ 3.87 (t, $\left.2 \mathrm{H}, \mathrm{CH}_{2}\right), 1.61-1.55\left(\mathrm{~m}, 2 \mathrm{H}, \mathrm{CH}_{2}\right), 0.91-0.87$ (t, $\left.3 \mathrm{H}, \mathrm{CH}_{3}\right) ;{ }^{13} \mathrm{C}-\mathrm{NMR}$ (DMSO- $d_{6}$ ): $\delta=162.4,152.3$, 151.0, 147.7, 143.7, 140.3, 127.8, 124.1, 78.1, 42.3, 21.1, 10.7 ppm; MS: $m / z(\%)=\mathrm{M}^{+}, 317$ (39), 288 (100), 261 (83), 190 (38), 168 (22), 153 (91), 152 (54), 151 (34), 149 (33), 127 (41), 110 (48), 103 (34), 89 (60), 84 (31), 76 (33), 68 (50); Anal. calcd. for $\mathrm{C}_{14} \mathrm{H}_{15} \mathrm{~N}_{5} \mathrm{O}_{4}(317.30)$ : C, 52.99; $\mathrm{H}$, 4.76; N, 22.07. Found: C, 53.15; H, 4.83; N, 22.24.

\section{4-(Dimethylamino)benzaldehyde(2,6-dioxo-3-pro- pyl-1,2,3,6-tetrahydro-pyrimidin-4-yl)hydrazone (5f)}

Yield: 76\%; m.p. $=234-235{ }^{\circ} \mathrm{C}$; IR $(\mathrm{KBr}) v_{\max }\left(\mathrm{cm}^{-1}\right): 3220$ (NH), 3045 (CH arom.), 2958, 2869 (CH aliph.), 1729, $1693(\mathrm{C}=\mathrm{O}), 1593(\mathrm{C}=\mathrm{N}), 1519(\mathrm{C}=\mathrm{C}), 855$ (p-substituted phenyl); ${ }^{1} \mathrm{H}-\mathrm{NMR}\left(\mathrm{DMSO}-d_{6}\right): 10.54(\mathrm{~s}, 1 \mathrm{H}, \mathrm{NH})$, 10.05 (s, $1 \mathrm{H}, \mathrm{NH}), 8.24(\mathrm{~s}, 1 \mathrm{H}, \mathrm{CH}), 7.53-7.51$ (d, $2 \mathrm{H}$, $\left.J=8.8 \mathrm{~Hz}, \mathrm{H}_{\text {arom }}\right), 6.76-6.74\left(\mathrm{~d}, 2 \mathrm{H}, J=8.8 \mathrm{~Hz}, \mathrm{H}_{\text {arom }}\right)$, $5.30(\mathrm{~s}, 1 \mathrm{H}, \mathrm{CH}-5), 3.87-3.83\left(\mathrm{t}, 2 \mathrm{H}, \mathrm{CH}_{2}\right), 2.97(\mathrm{~s}, 6 \mathrm{H}$, $\left.2 \mathrm{CH}_{3}\right), 1.59-1.54\left(\mathrm{~m}, 2 \mathrm{H}, \mathrm{CH}_{2}\right), 0.90-0.87\left(\mathrm{t}, 3 \mathrm{H}, \mathrm{CH}_{3}\right)$; ${ }^{13} \mathrm{C}-\mathrm{NMR}$ (DMSO- $d_{6}$ ): $\delta=162.4,158.1,154.0,151.9$, 147.6, 128.2, 121.3, 111.8, 76.3, 42.0, 41.1, 21.0, 10.7 ppm; MS: $m / z(\%)=\mathrm{M}^{+}, 315$ (100), 314 (10), 259 (8), $202(11)$, 188 (21), 173 (46), 148 (49), 147 (61), 146 (50), 145 (43), 133 (39), 132 (30); Anal. calcd. for $\mathrm{C}_{16} \mathrm{H}_{21} \mathrm{~N}_{5} \mathrm{O}_{2}$ (315.37): C, 60.94; H, 6.71; N, 22.21. Found: C, 61.23; H, 6.83; N, 22.37 .

\section{3-Aryl-8-propylpyrimido[5,4-e][1,2,4]tria- zine-5, $7(6 H, 8 H)$-diones $(6 a-e)$}

A solution of 4-substituted benzaldehyde(2,6-dioxo3-propyl-1,2,3,6-tetrahydropyrimidin-4-yl)hydrazones $(5 \mathbf{a}-\mathbf{e})(0.98 \mathrm{mmol})$ in glacial acetic acid $(4 \mathrm{~mL})$ is treated with sodium nitrite $(1.16 \mathrm{mmol})$ by heating under reflux for 3-4 h. The reaction mixture is evaporated under reduced pressure. The residue is treated with ethanol $(10 \mathrm{~mL})$; the formed precipitate is filtered, washed with ethanol, and crystallized from DMF/ethanol (1:2) to afford compounds $\mathbf{6 a}-\mathbf{e}$.

\section{3-Phenyl-8-propylpyrimido[5,4-e][1,2,4]tria- zine-5,7(6H,8H)-dione (6a)}

Yield: 71\%; m.p. $=290-291{ }^{\circ} \mathrm{C}$; IR $(\mathrm{KBr}) v_{\max }\left(\mathrm{cm}^{-1}\right)$ : $3173(\mathrm{NH}), 3024(\mathrm{CH}$ arom.), 2968, 2840 (CH aliph.), 1716, $1670(\mathrm{C}=\mathrm{O}), 1565(\mathrm{C}=\mathrm{N}), 1535(\mathrm{C}=\mathrm{C}) ;{ }^{1} \mathrm{H}-$ NMR (DMSO- $\left.d_{6}\right): 12.25(\mathrm{~s}, 1 \mathrm{H}, \mathrm{NH}), 8.42-8.40(\mathrm{~d}, 2 \mathrm{H}$, $\left.J=5.2 \mathrm{~Hz}, \mathrm{H}_{\text {arom }}\right), 7.62-7.61$ (m, 3H, arom.), 3.24-3.21 (t, $\left.2 \mathrm{H}, \mathrm{CH}_{2}\right), 1.68-1.63\left(\mathrm{~m}, 2 \mathrm{H}, \mathrm{CH}_{2}\right), 0.98-0.94(\mathrm{t}, 3 \mathrm{H}$, $\left.\mathrm{CH}_{3}\right) ;{ }^{13} \mathrm{C}-\mathrm{NMR}$ (DMSO- $\left.d_{6}\right): \delta=160.4,154.7,150.8$,
$149.4,146.2,134.2,131.3,129.3,127.1,42.4,20.6$, 11.0 ppm; MS: $m / z(\%)=\mathrm{M}^{+}, 283$ (16), 255 (20), 254 (38), 213 (17), 171 (13), 105 (100), 104 (13), 103 (10), 77 (29); Anal. calcd. for $\mathrm{C}_{14} \mathrm{H}_{13} \mathrm{~N}_{5} \mathrm{O}_{2}$ (283.28): C, 59.36; $\mathrm{H}, 4.63$; N, 24.72. Found: C, 59.58; H, 4.71; N, 24.89.

\section{3-(4-Chlorophenyl)-8-propylpyrimido[5,4-e][1,2,4]tria- zine-5,7(6H,8H)-dione (6b)}

Yield: $78 \%$; m.p. $=258-260{ }^{\circ} \mathrm{C}$; IR $(\mathrm{KBr}) v_{\max }\left(\mathrm{cm}^{-1}\right): 3135$ (NH), 3034 (CH arom.), 2972, 2839 (CH aliph.), 1725, $1672(\mathrm{C}=\mathrm{O}), 1586(\mathrm{C}=\mathrm{N}), 1553(\mathrm{C}=\mathrm{C}), 841$ (p-substituted phenyl); ${ }^{1} \mathrm{H}-\mathrm{NMR}$ (DMSO- $\left.d_{6}\right): 12.32(\mathrm{~s}, 1 \mathrm{H}, \mathrm{NH})$, 8.42-8.40 (d, $\left.2 \mathrm{H}, J=8.4 \mathrm{~Hz}, \mathrm{H}_{\text {arom }}\right), 7.69-7.67(\mathrm{~d}, 2 \mathrm{H}$, $\left.J=8.4 \mathrm{~Hz}, \mathrm{H}_{\text {arom }}\right), 4.25-4.21\left(\mathrm{t}, 2 \mathrm{H}, \mathrm{CH}_{2}\right), 1.76-1.71(\mathrm{~m}$, $\left.2 \mathrm{H}, \mathrm{CH}_{2}\right), 0.98-0.94\left(\mathrm{t}, 3 \mathrm{H}, \mathrm{CH}_{3}\right) ;{ }^{13} \mathrm{C}-\mathrm{NMR}$ (DMSO- $d_{6}$ ): $\delta=160.2,158.1,150.8,149.3,136.2,134.4,134.0,129.3$, 128.6, 42.9, 20.3, $11.0 \mathrm{ppm}$; MS: $m / z(\%)=\mathrm{M}+2,319(6)$, $\mathrm{M}^{+}, 317$ (17), 290 (24), 289 (26), 288 (64), 249 (14), 247 (40), 141 (31), 139 (100); Anal. calcd. for $\mathrm{C}_{14} \mathrm{H}_{12} \mathrm{ClN}_{5} \mathrm{O}_{2}$ (317.73): C, 52.92; H, 3.81; N, 22.04. Found: C, 53.14; H, $3.87 ; \mathrm{N}, 22.27$.

\section{3-(4-Bromophenyl)-8-propylpyrimido[5,4-e][1,2,4]tria- zine-5,7(6H,8H)-dione (6c)}

Yield: 76\%; m.p. $=250-252{ }^{\circ} \mathrm{C}$; IR $(\mathrm{KBr}) v_{\max }\left(\mathrm{cm}^{-1}\right): 3180$ (NH), 3084 (CH arom.), 2809 (CH aliph.), 1712, 1675 $(\mathrm{C}=\mathrm{O}), 1579(\mathrm{C}=\mathrm{N}), 1545(\mathrm{C}=\mathrm{C}) 845$ (p-substituted phenyl); ${ }^{1} \mathrm{H}-\mathrm{NMR}$ (DMSO- $d_{6}$ ): $12.22(\mathrm{~s}, 1 \mathrm{H}, \mathrm{NH}), 8.35-8.33$ $\left(\mathrm{d}, 2 \mathrm{H}, J=8.8 \mathrm{~Hz}, \mathrm{H}_{\text {arom }}\right), 7.84-7.82(\mathrm{~d}, 2 \mathrm{H}, J=8.8 \mathrm{~Hz}$, $\left.\mathrm{H}_{\text {arom }}\right), 4.25-4.21\left(\mathrm{t}, 2 \mathrm{H}, \mathrm{CH}_{2}\right), 1.77-1.71\left(\mathrm{~m}, 2 \mathrm{H}, \mathrm{CH}_{2}\right)$, 0.98-0.94 (t, $\left.3 \mathrm{H}, \mathrm{CH}_{3}\right) ;{ }^{13} \mathrm{C}-\mathrm{NMR}$ (DMSO- $\left.d_{6}\right): \delta=160.0$, $158.2,150.8,149.1,134.5,132.3,131.3,129.0,125.2$, 42.9, 20.3, $11.0 \mathrm{ppm}$; MS: $m / z(\%)=\mathrm{M}+2,364(2), \mathrm{M}^{+}$, 362 (3), 258 (29), 257 (15), 256 (15), 254 (24), 222 (100), 202 (31), 188 (20), 187 (22), 164 (22), 163 (21), 121 (24), 69 (64), 44 (78), 40 (53); Anal. calcd. for $\mathrm{C}_{14} \mathrm{H}_{12} \mathrm{BrN}_{5} \mathrm{O}_{2}$ (362.18): C, 46.43; H, 3.34; N, 19.34. Found: C, 46.71; H, $3.39 ; \mathrm{N}, 19.51$.

\section{3-(4-Hydroxyphenyl)-8-propylpyrimido[5,4-e][1,2,4]tria- zine-5,7(6H,8H)-dione (6d)}

Yield: $82 \%$; m.p. $=236-238{ }^{\circ} \mathrm{C}$; IR $(\mathrm{KBr}) v_{\max }\left(\mathrm{cm}^{-1}\right)$ : $3170(\mathrm{NH}), 3026(\mathrm{CH}$ arom.), 2833 (CH aliph.), 1722, $1677(\mathrm{C}=\mathrm{O}), 1558(\mathrm{C}=\mathrm{N}), 1537(\mathrm{C}=\mathrm{C}), 846$ (p-substituted phenyl); ${ }^{1} \mathrm{H}-\mathrm{NMR}$ (DMSO- $\left.d_{6}\right): 12.22(\mathrm{~s}, 1 \mathrm{H}, \mathrm{NH})$, 8.24-8.22 (d, $\left.2 \mathrm{H}, J=8.4 \mathrm{~Hz}, \mathrm{H}_{\text {arom }}\right), 6.74-6.72(\mathrm{~d}, 2 \mathrm{H}$, $\left.J=8.4 \mathrm{~Hz}, \mathrm{H}_{\text {arom }}\right), 3.79-3.76\left(\mathrm{t}, 2 \mathrm{H}, \mathrm{CH}_{2}\right), 1.69-1.63(\mathrm{~m}$, $\left.2 \mathrm{H}, \mathrm{CH}_{2}\right), 0.89-0.85\left(\mathrm{t}, 3 \mathrm{H}, \mathrm{CH}_{3}\right) ; \mathrm{MS}: m / z(\%)=\mathrm{M}^{+}, 299$ (17), 271 (22), 256 (20), 223 (34), 222 (40), 221 (100), 105 (60), 100 (94), 98 (76), 84 (33), 83 (29), 77 (29), 69 (31), 57 (26); Anal. calcd. for $\mathrm{C}_{14} \mathrm{H}_{13} \mathrm{~N}_{5} \mathrm{O}_{3}$ (299.28): C, 56.18; $\mathrm{H}$, 4.38; N, 23.40. Found: C, 56.34; H, 4.47; N, 23.62. 
3-(4-Nitrophenyl)-8-propylpyrimido[5,4-e][1,2,4]triazine-5,7(6H,8H)-dione (6c)

Yield: $70 \%$; m.p. $=267-268{ }^{\circ} \mathrm{C}$; IR $(\mathrm{KBr}) v_{\max }\left(\mathrm{cm}^{-1}\right)$ : $3165(\mathrm{NH}), 3067$ (CH arom.), 2974, 2811 (CH aliph.), 1720,1702 $(\mathrm{C}=\mathrm{O}), 1606(\mathrm{C}=\mathrm{N}), 1559(\mathrm{C}=\mathrm{C}), 1518$ $\left(\mathrm{NO}_{\text {2asymstr }}\right), 1346 \quad\left(\mathrm{NO}_{2 \text { symstr }}\right), 844$ ( $p$-substituted phenyl); ${ }^{1} \mathrm{H}-\mathrm{NMR}$ (DMSO- $d_{6}$ ): 12.31 (s, $\left.1 \mathrm{H}, \mathrm{NH}\right), 8.66-8.62$ $\left(\mathrm{d}, 2 \mathrm{H}, J=9.2 \mathrm{~Hz}, \mathrm{H}_{\text {arom }}\right), 8.46-8.43(\mathrm{~d}, 2 \mathrm{H}, J=9.2 \mathrm{~Hz}$, $\left.\mathrm{H}_{\text {arom }}\right), 4.25-4.21\left(\mathrm{t}, 2 \mathrm{H}, \mathrm{CH}_{2}\right), 1.75-1.70\left(\mathrm{~m}, 2 \mathrm{H}, \mathrm{CH}_{2}\right)$, $0.98-0.94\left(\mathrm{t}, 3 \mathrm{H}, \mathrm{CH}_{3}\right) ;{ }^{13} \mathrm{C}-\mathrm{NMR}$ (DMSO- $\left.d_{6}\right): \delta=162.0$, 156.9, 151,4, 151.2, 148.9, 140.4, 134.2, 128.2, 124.4, 42.8, 20.4, $11.1 \mathrm{ppm}$; MS: $m / z(\%)=\mathrm{M}^{+}, 328$ (11), 300 (18), 299 (63), 258 (32), 244 (21), 151 (42), 150 (100), 104 (18), 76 (20), 65 (21), 43 (23); Anal. calcd. for $\mathrm{C}_{14} \mathrm{H}_{13} \mathrm{~N}_{5} \mathrm{O}_{3}$ (328.28): C, 51.22; H, 3.68; N, 25.60. Found: C, 51.37; H, $3.65 ; \mathrm{N}, 25.81$.

\section{6-[2-(1-Arylethylidene)hydrazino]-1-propylpyrimi- dine-2,4(1H,3H)-diones $(\mathbf{7 a}, \boldsymbol{b})$}

A mixture of 6-hydrazinyl-1-propyluracil (4) $(2.72 \mathrm{mmol})$ and appropriate acetophenones $(2.72 \mathrm{mmol})$ in ethanol $(30 \mathrm{~mL})$ is stirred at room temperature for $3-4 \mathrm{~h}$. The formed precipitate is collected by filtration, washed with ethanol and crystallized from ethanol.

\section{6-[2-(1-Phenylethylidene)hydrazino]-1-propylpyrimi- dine-2,4(1H,3H)-dione (7a)}

Yield: 83\%; m.p. $=207-208{ }^{\circ} \mathrm{C}$; IR $(\mathrm{KBr}) v_{\max }\left(\mathrm{cm}^{-1}\right)$ : 3154 (NH), 3052 (CH arom.), 2963, 2870 (CH aliph.), 1715, $1691(\mathrm{C}=\mathrm{O}), 1602(\mathrm{C}=\mathrm{N}), 1499(\mathrm{C}=\mathrm{C})$; ${ }^{1} \mathrm{H}-\mathrm{NMR}$ $\left(\right.$ DMSO- $\left.d_{6}\right): 11.06(\mathrm{~s}, 1 \mathrm{H}, \mathrm{NH}), 8.96(\mathrm{~s}, 1 \mathrm{H}, \mathrm{NH}), 7.90-$ 7.82 (dd, $2 \mathrm{H}, J=9.2 \mathrm{~Hz}, \mathrm{H}_{\text {arom }}$ ), 7.44-7.43 (m, 3H, arom.), 5.39 (s, 1H, CH-5), 3.92-3.90 (t, 2H, $\left.\mathrm{CH}_{2}\right), 2.37(\mathrm{~s}, 3 \mathrm{H}$, $\left.\alpha-\mathrm{CH}_{3}\right), 1.68-1.63\left(\mathrm{~m}, 2 \mathrm{H}, \mathrm{CH}_{2}\right), 0.93-0.87\left(\mathrm{t}, 3 \mathrm{H}, \mathrm{CH}_{3}\right)$; ${ }^{13} \mathrm{C}-\mathrm{NMR}$ (DMSO- $d_{6}$ ): $\delta=166.5,162.5,161.1,151.2$, 137.6, 129.6, 128.5, 126.5, 78.8, 43.3, 20.2, 14.3, 11.3 ppm; MS: $m / z(\%)=\mathrm{M}^{+}, 286$ (44), 271 (44), 257 (21), 167 (36), 159 (64), 158 (64), 144 (45), 131 (40), 124 (20), 120 (100), 118 (48), 104 (72), 103 (38), 96 (21), 78 (30), 77 (96); Anal. calcd. for $\mathrm{C}_{15} \mathrm{H}_{18} \mathrm{~N}_{4} \mathrm{O}_{2}$ (286.32): C, 62.92; $\mathrm{H}, 6.34 ; \mathrm{N}$, 19.57. Found: C, 63.14; H, 6.39; N, 19.71 .

\section{6-[2-\{1-[4-(Dimethylamino)phenyl]ethylidene\}}

\section{hydrazino]-1-propylpyrimidine-2,4 $(1 \mathrm{H}, 3 \mathrm{H})$-dione (7b)}

Yield: $79 \%$; m.p. $=258-260{ }^{\circ} \mathrm{C}$; IR $(\mathrm{KBr}) v_{\max }\left(\mathrm{cm}^{-1}\right)$ : 3188 (NH), 3069 (CH arom.), 2961 (CH aliph.), 1704 $(\mathrm{C}=\mathrm{O}), 1593(\mathrm{C}=\mathrm{N}), 1504(\mathrm{C}=\mathrm{C}), 858$ (p-substituted phenyl); ${ }^{1} \mathrm{H}-\mathrm{NMR}$ (DMSO- $\left.d_{6}\right): 11.11(\mathrm{~s}, 1 \mathrm{H}, \mathrm{NH}), 9.13$ (s, $1 \mathrm{H}, \mathrm{NH}), 8.29-8.26$ (d, $2 \mathrm{H}, J=8.8 \mathrm{~Hz}, \mathrm{H}_{\text {arom }}$ ), 8.16-8.13 $\left(\mathrm{d}, 1 \mathrm{H}, J=8.8 \mathrm{~Hz}, \mathrm{H}_{\text {arom }}\right), 8.10-8.08(\mathrm{~d}, 1 \mathrm{H}, J=8.8 \mathrm{~Hz}$, $\mathrm{H}_{\text {arom }}$ ), 5.48 (s, $\left.1 \mathrm{H}, \mathrm{CH}-5\right), 4.02-3.94\left(\mathrm{t}, 2 \mathrm{H}, \mathrm{CH}_{2}\right), 3.29$ (s, $\left.6 \mathrm{H}, 2 \mathrm{CH}_{3}\right), 2.42\left(\mathrm{~s}, 3 \mathrm{H}, \alpha-\mathrm{CH}_{3}\right), 1.68-1.64\left(\mathrm{~m}, 2 \mathrm{H}, \mathrm{CH}_{2}\right)$, 0.94-0.89 (t, $\left.3 \mathrm{H}, \mathrm{CH}_{3}\right) ;{ }^{13} \mathrm{C}-\mathrm{NMR}$ (DMSO- $\left.d_{6}\right)$ : $\delta=166.5$,
162.5, 159.7, 151.1, 150.9, 144.0, 127.3, 123.6, 79.8, 43.4, 42.4, 20.2, 14.2, 11.3 ppm; MS: $m / z(\%)=\mathrm{M}^{+}, 329$ (2), 302 (100), 289 (8), 274 (21), 203 (34), 149 (21), 124 (12), 117 (55), 96 (21); Anal. calcd. for $\mathrm{C}_{17} \mathrm{H}_{23} \mathrm{~N}_{5} \mathrm{O}_{2}$ (329.39): C, 61.99; H, 7.04; N, 21.26. Found: C, 62.12; H, 7.18; N, 21.49 .

\section{5-[(Dimethylamino)methylene]-1-propylpyrimi- dine-2,4,6(1H,3H,5H)-trione 6-\{[1-phenylethylidene]hydra- zone\} (8)}

Method A A solution of 6-[2-(1-phenylethylidene) hydrazino]-1-propylpyrimidine-2,4(1H,3H)-dione (7a) $(0.7 \mathrm{mmol})$ in dimethylformamide-dimethylacetal $(4 \mathrm{~mL})$ is heated under reflux for $1 \mathrm{~h}$. The reaction mixture is evaporated under reduced pressure. The residue is treated with ethanol $(10 \mathrm{~mL})$; the formed precipitate is filtered, washed with ethanol, and crystallized from DMF/ethanol (1:3) to afford compound 8 .

Method B A solution of 6-[2-(1-phenylethylidene) hydrazino]-1-propylpyrimidine-2,4(1H,3H)-dione $(0.7 \mathrm{mmol})$ in dimethylformamide-dimethylacetal $(1.5 \mathrm{~mL})$ and DMF $(1.5 \mathrm{~mL})$ is heated under reflux for $15 \mathrm{~min}$. The reaction mixture is evaporated under reduced pressure. The residue is treated with ethanol $(10 \mathrm{~mL})$; the formed precipitate is filtered, washed with ethanol, and crystallized from DMF/ethanol (1:3) to afford compound 8.

Yield: method A 90\%, method B 94\%; m.p. $=220-$ $221{ }^{\circ} \mathrm{C}$; IR $(\mathrm{KBr}) v_{\max }\left(\mathrm{cm}^{-1}\right): 3136(\mathrm{NH}), 3030(\mathrm{CH}$ arom.), 2952, 2866 ( $\mathrm{CH}$ aliph.), 1690, 1656 (C=O), 1562 $(\mathrm{C}=\mathrm{N}), 1512(\mathrm{C}=\mathrm{C})$; ${ }^{1} \mathrm{H}-\mathrm{NMR}$ (DMSO-d6): 10.13 (s, $1 \mathrm{H}, \mathrm{NH}), 8.08(\mathrm{~s}, 1 \mathrm{H}, \mathrm{CH}), 7.73-7.71(\mathrm{~d}, 2 \mathrm{H}, J=7.6 \mathrm{~Hz}$, $\left.\mathrm{H}_{\text {arom }}\right), 7.45-7.36$ (m, 3H, arom.), 3.97-3.94 (t, $2 \mathrm{H}$, $\mathrm{CH}_{2}$ ), 3.19 (s, 3H, N-CH$\left.{ }_{3}\right), 3.05\left(\mathrm{~s}, 3 \mathrm{H}, \mathrm{N}-\mathrm{CH}_{3}\right), 2.39$ (s, 3H, $\mathrm{CH}_{3}$ ), 1.69-1.64 (m, 2H, $\left.\mathrm{CH}_{2}\right), 0.92-0.88(\mathrm{t}, 3 \mathrm{H}$, $\mathrm{CH}_{3}$ ); ${ }^{13} \mathrm{C}-\mathrm{NMR}$ (DMSO- $d_{6}$ ): $\delta=163.8,159.3,155.0$, 153.6, 151.0, 138.5, 128.6, 128.3, 125.4, 83.0, 46.2, 42.9, 42.7, 20.5, 14.0, 11.3 ppm; MS: $m / z(\%)=\mathrm{M}^{+}, 341(100)$, 325 (35), 297 (63), 296 (49), 160 (37), 123 (30), 103 (42), 91 (24), 77 (42), 42 (24); Anal. calcd. for $\mathrm{C}_{18} \mathrm{H}_{23} \mathrm{~N}_{5} \mathrm{O}_{2}$ (341.40): C, 63.32; H, 6.79; N, 20.51. Found: C, 62.95; H, 7.34; N, 20.39.

\section{5-Methyl-2-(1-phenylvinyl)-7-propyl-2H-pyrazolo[3,4-d] pyrimidine-4,6(5H,7H)-dione (9)}

Method $A$ A solution of 6-[2-(1-phenylethylidene) hydrazino]-1-propyl-pyrimidine-2,4(1H,3H)-dione

(7a) $(1.05 \mathrm{mmol})$ in dimethylformamide-dimethyl acetal $(1.5 \mathrm{~mL})$ and DMF $(1.5 \mathrm{~mL})$ is heated under reflux for $1 \mathrm{~h}$. The reaction mixture is evaporated under reduced pressure. The residue is treated with ethanol $(10 \mathrm{~mL})$, the formed precipitate is filtered, washed with ethanol, and crystallized from DMF/ethanol (1:3) to afford compound 9. 
Method B A mixture of 6-[2-(1-phenylethylidene) hydrazino]-1-propyl- pyrimidine-2,4(1H,3H)-dione (7a) $(1.05 \mathrm{mmol})$ and dimethylformamide-dimethylacetal $(3 \mathrm{~mL})$ is heated under reflux for $12 \mathrm{~h}$. The reaction mixture is evaporated under reduced pressure. The residue is treated with ethanol $(10 \mathrm{~mL})$, the formed precipitate is filtered, washed with ethanol, and crystallized from DMF/ ethanol (1:3) to afford compound 9.

Method C A mixture of 5-[(dimethylamino)methylene]1-propylpyrimidine-2,4,6(1H,3H,5H)-trione 6-\{[1-phenylethylidene]hydrazone $(8)(1.17 \mathrm{mmol})$ and DMF-DMA $(3 \mathrm{~mL})$ is heated under reflux for $1 \mathrm{~h}$. The reaction mixture is evaporated under reduced pressure. The residue is treated with ethanol $(15 \mathrm{~mL})$, the formed precipitate is filtered, washed with ethanol, and crystallized from DMF/ ethanol (1:3) to afford compound 9.

Yield: method A 82\%, method B 74\%, method C 92\%; m.p. $=148-149{ }^{\circ} \mathrm{C}$; IR (KBr) $v_{\max }\left(\mathrm{cm}^{-1}\right): 3095(\mathrm{CH}$ arom.) 2950, 2875 ( $\mathrm{CH}$ aliph.), 1760, $1701(\mathrm{C}=\mathrm{O}), 1591$ $(\mathrm{C}=\mathrm{N}), 1546(\mathrm{C}=\mathrm{C}) ;{ }^{1} \mathrm{H}-\mathrm{NMR}$ (DMSO-d6): 8.60 (s, $1 \mathrm{H}, \mathrm{CH}-3), 7.44-7.36$ (m, $5 \mathrm{H}$, arom.), 5.71-5.61 (dd, $\left.2 \mathrm{H},=\mathrm{CH}_{2}\right), 3.87-3.83\left(\mathrm{t}, 2 \mathrm{H}, \mathrm{CH}_{2}\right), 3.23\left(\mathrm{~s}, 3 \mathrm{H}, \mathrm{CH}_{3}\right)$, 1.69-1.64 (m, $\left.2 \mathrm{H}, \mathrm{CH}_{2}\right), 0.86-0.83\left(\mathrm{t}, 3 \mathrm{H}, \mathrm{CH}_{3}\right) ;{ }^{13} \mathrm{C}-$ NMR (DMSO-d6): $\delta=157.8,151.0,150.3,144.6,134.2$, 131.8, 129.5, 128.5, 127.3, 109.0, 101.7, 44.7, 27.6, 20.2, $11.0 \mathrm{ppm} ; \mathrm{MS}: m / z(\%)=\mathrm{M}^{+}, 310$ (100), 268 (75), 267 (54), 224 (65), 122 (64), 103 (67),77 (34); Anal. calcd. for $\mathrm{C}_{17} \mathrm{H}_{18} \mathrm{~N}_{4} \mathrm{O}_{2}$ (310.35): C, 65.79; H, 5.85; N, 18.05. Found: C, 66.01; H, 5.89; N, 18.24.

\section{2,5-Dimethyl-7-propyl-2H-pyrazolo[3,4-d]pyrimi- dine-4,6(5H,7H)-dione (11)}

A solution of 6-hydrazinyl-1-propyluracil (4) $(1.63 \mathrm{mmol})$ in dimethylformamide-dimethylacetal $(1.5 \mathrm{~mL})$ and DMF $(1.5 \mathrm{~mL})$ is heated under reflux for $1 \mathrm{~h}$. The reaction mixture is evaporated under reduced pressure. The residue is treated with ethanol $(10 \mathrm{~mL})$, the formed precipitate is filtered, washed with ethanol, and crystallized from DMF/ethanol (1:3) to afford compound 11.

Yield: $88 \%$; m.p. $=167-169{ }^{\circ} \mathrm{C}$; IR (KBr) $v_{\max }\left(\mathrm{cm}^{-1}\right)$ : 3094 ( $\mathrm{CH}$ arom.), 2951, 2877 ( $\mathrm{CH}$ aliph.), 1751, 1698 $(\mathrm{C}=\mathrm{O}), 1586(\mathrm{C}=\mathrm{N}), 1544(\mathrm{C}=\mathrm{C})$; ${ }^{1} \mathrm{H}-\mathrm{NMR}$ (DMSO$\left.d_{6}\right): 8.41(\mathrm{~s}, 1 \mathrm{H}, \mathrm{CH}-3), 3.88\left(\mathrm{~s}, 1 \mathrm{H}, \mathrm{N}(2)-\mathrm{CH}_{3}\right), 3.87-3.83$ (t, $\left.2 \mathrm{H}, \mathrm{CH}_{2}\right), 3.19\left(\mathrm{~s}, 3 \mathrm{H}, \mathrm{N}(5)-\mathrm{CH}_{3}\right), 1.70-1.65(\mathrm{~m}, 2 \mathrm{H}$, $\left.\mathrm{CH}_{2}\right), 0.90-0.86\left(\mathrm{t}, 3 \mathrm{H}, \mathrm{CH}_{3}\right) ;{ }^{13} \mathrm{C}-\mathrm{NMR}$ (DMSO- $\left.d_{6}\right)$ : $\delta=157.9,151.0,149.8,131.8,100.1,44.7,40.4,27.5$, 20.3, $11.0 \mathrm{ppm}$; MS: $m / z(\%)=\mathrm{M}^{+}, 222$ (30), 180 (52), 135 (100), 123 (28), 42 (15); Anal. calcd. for $\mathrm{C}_{10} \mathrm{H}_{14} \mathrm{~N}_{4} \mathrm{O}_{2}$ (222.24): C, 54.04; H, 6.35; N, 25.21. Found: C, 54.13; H, 6.43; N, 25.45.

\section{Biological investigation}

\section{Evaluation of the antitumor activity} Mammalian cell lines

The cell line that used in this study was human lung carcinoma cell line (A549 cells) is obtained from tissue culture Unit, VACSERA, Cairo, Egypt.

The mammalian cells are propagated in Dulbecco's modified Eagle's [41] medium (DMEM) or RPMI-1640 depending on the type of cell line supplemented with $10 \%$ heat-inactivated fetal bovine serum, $1 \% \mathrm{~L}$-glutamine, HEPES buffer and $50 \mu \mathrm{g} / \mathrm{mL}$ gentamycin. All cells are maintained at $37{ }^{\circ} \mathrm{C}$ in a humidified atmosphere with $5 \% \mathrm{CO}_{2}$ and are subcultured two times a week along experimentation.

\section{i-Antitumor activity evaluation using viability assay}

Antitumor activity assay is carried out according to the method described literature [42]. All the experiments concerning the cytotoxicity evaluation are performed and analyzed by tissue culture unit at the regional center for mycology and biotechnology RCMB, Al-Azhar University, Cairo, Egypt.

\section{Procedure}

The A549 tumor cells are seeded in 96-well plate in $100 \mu \mathrm{L}$ of growth medium at a cell concentration of $1 \times 10^{4}$ cells/well. After $24 \mathrm{~h}$ of seeding, the monolayers are then washed with sterile phosphate buffered saline $(0.01 \mathrm{M} \mathrm{pH} 7.2)$ and simultaneously the cells are treated with $100 \mu \mathrm{L}$ from different dilutions of the test sample in fresh maintenance medium and incubated at $37^{\circ} \mathrm{C}$. Different two-fold dilutions of the tested compound (started from 500 to $0.25 \mu \mathrm{M}$ ) are added to confluent cell monolayers dispensed into 96-well, flat-bottomed microtiter plates (Falcon, NJ, USA) using a multichannel pipette. The microtiter plates are incubated at $37^{\circ} \mathrm{C}$ in a humidified incubator with $5 \% \mathrm{CO}_{2}$ for a period of $72 \mathrm{~h}$. Untreated cells are served as controls. Three independent experiments are performed each containing six replicates for each concentration of the tested samples. The cytotoxic effects of the tested compounds are then measured using crystal violet staining viability assay. Briefly, after $72 \mathrm{~h}$ of treatment, the medium is removed, $100 \mu \mathrm{L}$ of $0.5 \%$ of crystal violet in $50 \%$ methanol is added to each well and incubated for $20 \mathrm{~min}$ at room temperature and subsequently excess dye is washed out gently by distilled water. The plate is allowed to dry then the viable crystal violet-stained cells are lysed using 33\% glacial acetic acid solution. Absorbance at $570 \mathrm{~nm}$ is then measured in each well using microplate reader (Sunrise, TECAN, Inc, USA). Toxoflavin and 5-fluorouracil are used as positive 
control. The absorbance is proportional to the number of surviving cells in the culture plate.

\section{Conclusions}

A series of newly synthesized compounds of substituted benzaldehyde-pyrimidin-4-yl)hydrazones $(\mathbf{5 a}-\mathbf{f})$, pyrimido[5,4-e][1,2,4]triazines $\mathbf{6 a}-\mathbf{e}$, arylethylidenehydrazinylpyrimidines $\mathbf{7 a , b}$ and pyrazolopyrimidines $\mathbf{9 , 1 1}$ are prepared via a simple method starting from the substrate 6-hydrazinyl-1-propyluracil (4). The synthesized compounds exhibited good cytotoxic activity against human lung carcinoma (A549) cell line and the highest effect is measured for compound $\mathbf{6 b}$ with $\mathrm{IC}_{50}$ value $3.6 \mu \mathrm{M}$, followed by compounds $\mathbf{9}, \mathbf{5 a}, \mathbf{8}, \mathbf{5 e}, \mathbf{6 e}, \mathbf{5 b}, \mathbf{5 f}$, $7 \mathbf{a}, \mathbf{5 c}, \mathbf{6 c}, \mathbf{7 b}, \mathbf{6 a}, \mathbf{1 1}, \mathbf{5 d}$ and $\mathbf{6 d}$ with $\mathrm{IC}_{50}$ values of 26.3 , 26.8, 28.4, 49.3, 53.8, 54.7, 60.2, 60.5, 74.3, 81.5, 104.6, 107.1, 123, 238.7, and 379.4 $\mu \mathrm{M}$, compared with reference drug 5-fluorouracil $(10.5 \mu \mathrm{M})$.

\section{Authors' contributions}

SAEK formulated the research idea, conceived and prepared the manuscript: SAEK performed the experiments and analyzed the data; SAEK wrote the paper. The author read and approved the final manuscript.

\section{Author details}

${ }^{1}$ Department of Pharmaceutical Organic Chemistry, Faculty of Pharmacy (Girls), Al-Azhar University, Nasr City, Cairo 11651, Egypt. ${ }^{2}$ Department of Medical Chemistry, Faculty of Applied Medical Sciences (Female Section), Jazan University, Jazan 45142, Saudi Arabia.

\section{Acknowledgements}

The Author wishes to thank Dr. Mahmoud Elaasser for carrying out and drafting the biological activity of this work; who is an associate professor at the Regional Center for Mycology and Biotechnology at Al-Azhar University, Cairo, Egypt.

\section{Competing interests}

The author declares no competing interests.

\section{Ethics approval and consent to participate}

Not applicable.

\section{Publisher's Note}

Springer Nature remains neutral with regard to jurisdictional claims in published maps and institutional affiliations.

Received: 3 March 2018 Accepted: 30 April 2018

Published online: 23 May 2018

\section{References}

1. Izmest'ev AN, Gazieva GA, Sigay NV, Serkov SA, Karnoukhova VA, Kachala V, Shashkov AS, Zanin IE, Kravchenko AN, Makhova NN (2016) An effective one-pot access to polynuclear dispiroheterocyclic structures comprising pyrrolidinyloxindole and imidazothiazolotriazine moieties via a 1,3-dipolar cycloaddition strategy, Beilstein. J Org Chem 12:2240-2249

2. Ruanpanun P, Laatsch H, Tangchitsomkid N, Lumyong S (2011) Nematicidal activity of fervenulin isolated from a nematicidal actinomycete, Streptomyces sp. CMU-MH021, on Meloidogyne incognita. World J Microbiol Biotechnol 27:1373-1380

3. Nagamatsu T, Yamasaki H, Hirota T, Yamato M, Kido Y, Shibata M, Yoneda F (1993) Syntheses of 3-substituted 1-methyl-6-phenylpyrimido[5,4-e]
$[1,2,4]$ triazine-5,7(1H,6H)-diones (6-phenyl analogs of toxoflavin) and their 4-oxides, and evaluation of antimicrobial activity of toxoflavins and their analogs. Chem Pharm Bull 41:362-368

4. Kiselev OI, Deyeva EG, Melnicova TI, Kozeletskaia KN, Kiselev AS, Rusinov VL, Charushin VN, Chupahin ON (2012) A new antiviral drug triazavirin: results of phase II clinical trial. Vopr Virusol 57:9-12

5. Abdel-Rahman RM, Seada M, Fawzy M, El-Baz I (1994) Synthesis of some new 1,6-dihydro-3-substituted 6-spiro-(9'-fluorene)-1,2,4-triazin-5-(4H)ones as potential anti HIV and anticancer drugs. Pharmazie 49:729-733

6. Abdel-Rahman RM, Seada M, Fawzy M, El-Baz I (1994) Synthesis of some new 1,6-dihydro-3-substituted-6-spiro-(9'-fluorene)-1,2,4-triazin-5(4H)-on es as potential anti HIV and anticancer drugs. Boll Chim Farm 133:381-388

7. Abd El-Moneim M, Hasanen JA, El-Deen IM, Abd El-Fattah W (2015) Synthesis of fused 1,2,4-triazines as potential antimicrobial and antitumor agents. Res Chem Intermed 41:3543-3561

8. El-Nassan HB (2012) Synthesis, antitumor activity and SAR study of novel [1,2,4]triazino[4,5-a]benzimidazole derivatives. Eur J Med Chem 53:22-27

9. Abraham S, Hadd MJ, Tran L, Vickers T, Sindac J, Milanov ZV, Holladay MW, Bhagwat SS, Hua H, Ford Pulido JM, Cramer MD, Gitnick D, James J, Dao A Belli B, Armstrong RC, Treiber DK, Liu G (2011) Novel series of pyrrolotriazine analogs as highly potent pan-Aurora kinase inhibitors. Bioorg Med Chem Lett 21:5296-5300

10. Crespin L, Biancalana L, Morack T, Blakemore DC, Ley SV (2017) One-pot acid-catalyzed ring opening/cyclization/oxidation of aziridines with $N$-tosylhydrazones: access to 1,2,4-triazines. Org Lett 19:1084-1087

11. Sztanke K, Pasternak K, Rajtar B, Sztanke M, Majek M, Polz-Dacewicz M (2007) Identification of antibacterial and antiviral activities of novel fused 1,2,4-triazine esters. Bioorg Med Chem. 15:5480-5486

12. Culakova H, Dzugasova V, Gbelska Y, Subik J (2013) Antibacterial activity of CTBT (7-chlorotetrazolo[5,1-c] benzo[1,2,4]triazine) generating reactive oxygen species. Microbiol Res 168:147-152

13. Yurttaş L, Demirayak S, Ilgın S, Atı O (2014) In vitro antitumor activity evaluation of some 1,2,4-triazine derivatives bearing piperazine amide moiety against breast cancer cells. Bioorg Med Chem 22:6313-6323

14. Karczmarzyk Z, Wysocki W, Urbaczy-Lipowsa Z, Kalici P, Bielawsa A, Bielawsi K, Ławeca J (2015) Synthetic approaches for sulfur derivatives containing 1,2,4-triazine moiety: their activity for in vitro screening towards two human cancer cell lines. Chem Pharm Bull. 63:531-537

15. Iranneja H, Nadri H, Naderi N, Rezaeian SN, Zafari N, Foroumadi A (2015) Anticonvulsant activity of 1,2,4-triazine derivatives with pyridyl side chain: synthesis, biological, and computational study. Med Chem Res 24(6):2505-2513

16. Khoshneviszadeh M, Ghahremani MH, Foroumadi A, Miri R, Firuzi O, Madadkar-Sobhani A, Edraki N, Parsa M, Shafiee A (2013) Design, synthesis and biological evaluation of novel anti-cytokine 1,2,4-triazine derivatives. Bioorg Med Chem 21:6708-6717

17. Rusinov VL, Egorov IN, Chupakhin ON, Belanov EF, Bormotov NI, Serova OA (2012) Synthesis and antiviral activity of 1,2,4-triazine derivatives. Pharm Chem J 45:655-659

18. Sidwell RW, Dixon GJ, Sellers SM, Schabel FM (1968) In vivo antiviral properties of biologically active compounds. Appl Microbiol 16(2):370-392

19. Falke D, Rada B (1970) 6-Azauridine as an inhibitor of the synthesis of Herpesvirus hominis. Actavirologica 14(2):115-123

20. Creasey WA, Fink ME, Handschumacker RE, Calabresi P (1963) Clinical and pharmacological studies with 2',3',5'-triacetyl-6-azauridine. Cancer Res 23:444-453

21. Walters TR, Aur RJA, Hernandez K, Vietti T, Pinkel D (1972) 6-Azauridine in combination chemotherapy of childhood acute myelocytic leukemia. Cancer 29(4):1057-1060

22. Sarkar U, Glaser R, Parsons ZD, Barnes CL, Gates KS (2010) Synthesis, crystal structure, and rotational energy profile of 3-cyclopropyl-1,2,4benzotriazine 1,4-di-N-oxide. J Chem Crystallogr 40(7):624-629

23. Kumar R, Singh AD, Singh J, Singh H, Roy RK, Chaudhary A (2014) 1,2,3-Triazine scaffold as a potent biologically active moiety: a mini review. Mini Rev Med Chem 14(1):72-83

24. Bulychev Yu, YakunIna N, Shorshnev S, Yeslpov S (1996) Poster sessions: 22. Drug design, synthesis, acquisition and structure-activity relationships "synthesis and cytotoxic activity of alkyl and hydroxyalkyl derivatives of reumycin". Ann Oncol 7:105-113 
25. Ludovic V, Groleau M, Dekimpe V, Deziel E (2007) Burkholderia diversity and versatility: an inventory of the extracellular products. J Microbiol Biotechnol 17(9):1407-1429

26. Goh KC, Wang H, Yu N, Zhou Y, Zheng Y, Lim Z, Sangthongpitag K, Fang L, Du M, Wang X (2004) PLK1 as a potential drug target in cancer therapy. Drug Dev Res 62:349-361

27. Nagamatsu T (2001) Syntheses, transformation, and biological activities of 7-azapteridine antibiotics: toxoflavin, fervenulin, reumycin and their analogs. Recent Res Dev Org Bioorg Chem 4:97-121

28. Aly AA, Gad El-Karim IA (2011) facile synthesis of new pyrazolopyrimidine derivatives of potential biosignificant interest. J Korean Chem Soc 55(5):781-786

29. Tollefson MB, Acker BA, Jacobsen EJ, Hughes RO, Walker JK, Fox DNA, Palmer MJ, Freeman SK, Yu Y, Bond BR (2010) 1-(2-Ethoxyethyl)$1 \mathrm{H}$-pyrazolo[4,3-d]pyrimidines as potent phosphodiesterase 5 (PDE5) inhibitors. Bioorg Med Chem Lett 20(10):3120-3124

30. Kumar R, Joshi YC (2010) Synthesis, spectral studies and biological activity of novel 1H-1,4-diazepine derivatives. Indian J Chem Sect B 49B(1):84-88

31. Ivachtchenko AV, Dmitriev DE, Golovina ES, Dubrovskaya ES, Kadieva MG, Koryakova AG, Kysil VM, Mitkin OD, Tkachenko SE, Okun IM, Vorobiov AA (2010) Synthesis of cycloalkane-annelated 3-phenylsulfonyl-pyrazolo[1,5a]pyrimidines and their evaluation as 5-HT6 receptor antagonists. Bioorg Med Chem Lett 20(7):2133-2136

32. Bakavoli M, Bagherzadeh G, Vaseghifar M, Shiri A, Pordel M, Mashreghi M, Pordeli P, Araghi M (2010) Molecular iodine promoted synthesis of new pyrazolo[3,4- $d]$ pyrimidine derivatives as potential antibacterial agents. Eur J Med Chem 45(2):647-650

33. Curran KJ, Verheijen JC, Kaplan J, Richard DJ, Toral-Barza L, Hollander I, Lucas J, Ayral-Kaloustian S, Yu K, Zask A (2010) Pyrazolopyrimidines as highly potent and selective, ATP-competitive inhibitors of the mammalian target of rapamycin (mTOR): optimization of the 1-substituent. Bioorg Med Chem Lett 20(4):1440-1444
34. Kim I, Song JH, Park CM, Jeong JW, Kim HR, Ha JR, No Z, Hyun YL, Cho YS, Kang NS, Jeon DJ (2010) Design, synthesis, and evaluation of 2-aryl-7(3',4'-dialkoxyphenyl)-pyrazolo[1,5-a]pyrimidines as novel PDE-4 inhibitors. Bioorg Med Chem Lett 20(3):922-926

35. Ali HI, Fujita T, Akaho E, Nagamatsu T (2010) A comparative study of AutoDock and PMF scoring performances, and SAR of 2-substituted pyrazolotriazolopyrimidines and 4-substituted pyrazolopyrimidines as potent xanthine oxidase inhibitors. J Comput Aided Mol Des 24(1):57-75

36. Schenone S, Brullo C, Bruno O, Bondavalli F, Mosti L, Maga G, Crespan E, Carraro F, Manetti F, Tintori C, Botta M (2008) Synthesis, biological evaluation and docking studies of 4-amino substituted $1 \mathrm{H}$-pyrazolo[3,4-d] pyrimidines. Eur J Med Chem 43(12):2665-2676

37. Cresswell RM, Wood HCS (1960) The biosynthesis of pteridines. Part I. The synthesis of riboflavin. J Chem Soc. 4768-4775

38. El-Kalyoubi S, Agili F (2016) A novel synthesis of fused uracils: indenopyrimidopyridazines, pyrimidopyridazines, and pyrazolopyrimidines for antimicrobial and antitumor evalution. Molecules. https://doi.org/10.3390/ molecules21121714

39. Furukawa Y, Maki Y, (1986) 3-Aminopyrazolo[3,4-d]pyrimidine derivatives and production thereof. US Patent 4,603,203

40. Youssif S, Assy M (1996) Fervenulin, 4-deazafervenulin and 5-deazaalloxazine analogues: Synthesis and Antimicribial activity. J Chem Res 442:2546

41. Halawa AH, Elaasser MM, El Kerdawy AM, Abd El-Hady AMAl, Emam HA, El-Agrody AM (2017) Anticancer activities, molecular docking and structure-activity relationship of novel synthesized $4 \mathrm{H}$-chromene, and 5H-chromeno[2,3-d]pyrimidine candidates. Med Chem Res 26(10):2624-2638

42. Mosmann T (1983) Rapid colorimetric assay for cellular growth and survival: application to proliferation and cytotoxicity assays. J Immunol Methods 65:55-63

\section{Submit your manuscript to a SpringerOpen ${ }^{\circ}$ journal and benefit from:}

- Convenient online submission

- Rigorous peer review

- Open access: articles freely available online

- High visibility within the field

- Retaining the copyright to your article

Submit your next manuscript at springeropen.com 